\title{
PENDIDIKAN ISLAM SEBAGAI UPAYA MA'RIFATULLAH
}

\author{
${ }^{1}$ Asep Abdul Aziz, ${ }^{2}$ Nurti Budiyanti, ${ }^{3}$ Nurwadjah Ahmad, ${ }^{4}$ Andewi Suhartini, ${ }^{5}$ Ari Prayoga \\ ${ }_{1,3,4}$ UIN Sunan Gunung Djati Bandung, Jl. Soekarno-Hatta Cimincrang, Indonesia \\ 1email: asepabdulaziz19993@gmailcom \\ 3email: nurwadjah.ahmad@gmail.com \\ ${ }^{4}$ email: andewi.suhartini@uinsgd.ac.id \\ ${ }^{2}$ Universitas Pendidikan Indonesia,Jl. Dr. Setiabudi No.229, Isola, Indonesia \\ email: nurtibudiyanti@upi.edu \\ ${ }^{5}$ Perkumpulan Sarjana Manajemen Pendidikan Islam Indonesia, Kom. Permata Biru Blok I No.33, \\ Indonesia \\ email: ariprayoga@madrasah.id
}

\begin{abstract}
Facing this modern era, ma'rifatullah is faced with increasingly complex life challenges. The reality of education also continues to experience severe moral degradation. The reason is one of them is due to the shifting of part of human thought from virtuous life orientation to the pursuit of hedonic and materialistic lifestyles. The purpose of this research is to uncover and analyze a synergistic approach that can revive human interest in opening and studying the values of ma'rifatullah and the space to apply them especially in Islamic education referring to the Koran and Hadith. The method to be used is the study of literature. The type of data used is secondary data with literature study data collection techniques. Based on the findings and analysis in this study, namely; firstly, ma'rifatullah is the main goal of developing all human potential, when a human manifests his spiritual power, then easily deliver it to ma'rifatullah. Second, the educational implications of this concept include the goals, roles, functions, principles, educators, students, material, methods and educational media. All of that must have a positive influence on the mind and heart in increasing all the potential possessed by humans. Thus, all the educational components are directed towards ma'rifatullāh.
\end{abstract}

Keywords: education, islam, ma'rifatullah

\section{PENDAHULUAN}

Pendidikan merupakan hal yang dianggap paling utama dalam proses pembentukan manusia seutuhnya yang sesuai dengan aturan atau syari'at Islam. Berbicara mengenai pendidikan maka tidak akan terlepas dari pembahasan mengenai objek dan subjek pendidikan serta pendidikan seperti apa yang efektif dan semestinya diterapkan dalam mendidik manusia itu sendiri. Sebagai objek dan subjek pendidikan, manusia dituntut untuk memahami seperti apa manusia yang memiliki nilai manusiawi. Sehingga baik objek atau subjek pendidikan mengetahui seperti apa yang akan ditempuh atau yang akan menjadi tujuannya dalam proses pendidikan. Dengan mengetahui semua itu maka sudah akan menjadi kepastian, dalam proses pendidikan akan berjalan dengan baik dan lancar. Selanjutnya yang tidak kalah pentingnya mengenai jenis atau pendidikan seperti apa yang cocok atau relevan digunakan sehingga dengan proses pendidikan yang digunakan 
akan menghasilkan para lulusan yang memiliki nilai intelektual, emosional dan spiritual di atas rata-rata ${ }^{1}$.

Menghadapi zaman modern ini, ma'rifatullah dihadapkan pada tantangan kehidupan yang semakin kompleks. Hal tersebut membuat manusia terkadang melupakan kewajiban suci menjalankan tugas dan fungsinya sebagai 'abid di muka bumi. Penyebab salah satunya karena mulai bergesernya sebagian pemikiran manusia dari orientasi hidup beramal kebajikan menjadi mengejar gaya hidup hedonis dan materialistik. Jika melihat realita yang ada sekarang, terutama di Indonesia sendiri. kita bisa merasakan bahwa pendidikan yang dipakai di Negara kita ini dirasa kurang efektif, tetapi bukan berarti pendidikan yang ada sekarang tidak cocok, hanya saja dirasa kurang efektif. Kita sering mendengar berita-berita yang bersifat negatif yang menghantui para siswa atau mahasiswa seperti tawuran yang sudah menjadi kebiasaan, geng motor, pergaulan bebas, hedonis, dll. Nilai-nilai dari ma'rifatullah sendiri sedikit demi sedikit mulai ditinggalkan. Untuk itu, dalam jaman kontemporer ini, dirasa perlu dicari pendekatan sinergis yang dapat membangkitkan kembali minat manusia membuka dan mempelajari nilai-nilai ma'rifatullah serta ruang untuk mengaplikasikanya terutama dalam pendidikan Islam².

Pendekatan yang dipakai haruslah mampu merepresentasikan nilai-nilai yang terkandung dalam ma'rifatullah yang mempunyai relevansi kuat dengan jaman kekinian. Antara ma'rifatullah dengan pendekatan yang dipakai, dituntut selaras dengan visi pendidikan Islam. Sebagaimana diketahui bahwa visi pendidikan Islam tak lepas dari menyiapkan peserta didik untuk mengenal, memahami, menghayati, hingga pada proses mengimani ajaran-ajaran Islam dalam kehidupannnya, atau bisa dikatakan suatu usaha untuk mengubah tingkah laku individu dalam kehidupan pribadinya, kehidupan kemasyarakatannya dan kehidupan alam sekitarnya melalui proses pendidikan yang dilandasi oleh nilai-nilai Islami, agar nantinya peserta didik mampu, sanggup dan terampil dalam menjalankan kehidupan sebagai upaya menjaga kelangsungan hidup dan perkembangannya. Pendidikan Islam di Indonesia dikenal dengan ciri khasnya yaitu pondok pesantren. Berikut perkembangan secara kuantitas kelembagaan pendidikan Islam khususnya pesantren dan diniyah ${ }^{3}$.

${ }^{1}$ Muhammad Rusmin B, “Konsep dan Tujuan Pendidikan Islam,” Jurnal Taklim 06, no. 01 (2004): $72-80$.

${ }^{2}$ Murni, “Konsep Ma'rifatullah Menurut Al-Ghazali (Suatu Kajian Tentang Implementasi Nilai-Nilai Akhlak Al-Karimah)," Ar-Raniry: International Journal of Islamic Studies 02, no. 01 (2015): 123-146, www.journalarraniry.com. (2008).

${ }^{3}$ Sri Haningsih, "Peran Strategis Pesantren, Madrasah dan Sekolah Islam di Indonesia," el-Tarbawi 
Tabel 1. Data Rekapitulasi Lembaga Pondok Pesantren dan Diniyah di Indonesia ${ }^{4}$

\begin{tabular}{llll}
\hline No & Jenis Pendidikan & Jenjang Pendidikan & Jumlah Lembaga \\
\hline \multicolumn{2}{l}{ Pondok Pesantren (PP) } & & \\
\hline 1 & Pendidikan Formal & Ma'had Aly & 44 \\
\cline { 3 - 3 } & SPM Ulya & 66 \\
\cline { 3 - 3 } & SPM Wustha & 55 \\
\cline { 3 - 3 } & SPM Ula & 3 \\
\cline { 3 - 3 } & PDF Ulya & 63 \\
\cline { 3 - 3 } & PDF Wustha & 43 \\
\cline { 3 - 3 } & PDF Ula & 0 \\
\hline 2 & Pendidikan Kesetaraan & PK-PPS Ulya & 48 \\
\cline { 3 - 3 } & & PK-PPS Wustha & 596 \\
\cline { 3 - 3 } & & PK-PPS Ula & 87 \\
\hline 3 & Pendidikan Non & Pengajian Kitab & 12.775 \\
\cline { 3 - 3 } & Formal & Kuning & \\
\hline
\end{tabular}

\begin{tabular}{llll}
\hline \multicolumn{2}{l}{ Pesantren Diniyah (PD) } & \\
\hline 4 & $\begin{array}{l}\text { Pendidikan Non } \\
\text { Formal }\end{array}$ & MDT Ulya & 1 \\
\cline { 3 - 3 } & MDT Wustha & 4 \\
\cline { 2 - 3 } & MDT Ula & 265 \\
\cline { 2 - 3 } & LPQ & 160.829 \\
\hline & Total & 174.614
\end{tabular}

Masalah besar yang dihadapi dalam kaitannya antara ma'rifatullah dan pendidikan Islam, salah satunya adalah pengaitan nilai-nilai ma'rifatullah dalam alam nyata. Ini sebuah problem mendasar yang perlu segera membutuhkan solusi penyelesaian. Tentunya solusi yang dibutuhkan harus relevan dan tepat sasaran. Kondisi tersebut membutuhkan kerja keras dan kerja cerdas dari semua komponen dan elemen pendidikan tanpa terkecuali mulai dari pendidik, sistem, metodologi, pola kebijakan, dan sebagainya. Pengajaran ma'rifatullah dalam pendidikan Islam belum banyak diperkenalkan bagi peserta didik. Hal ini terjadi karena minimnya terbatasnya informasi mengenai ma'rifatullah itu sendiri. Sehingga ma'rifatullah sendiri dikalangan umat muslim sendiri terasa asing, bahkan ada yang tidak tahu sama sekali. Bisa jadi karena terbatasnya informasi yang ada itulah, membuat nilai tawar ma'rifatullah dalam membangun pendidikan Islam masih banyak dipertanyakan. Hal itu tentunya sangat wajar mengingat ma'rifatullah belum begitu

4 Bagian Data Sistem Informasi dan Humas, "EMIS Dashboard Pendis Kemenag Rekapitulasi Data Pesantren dan Diniyah" (Jakarta: Dirjen Pendidikan Islam, Juli 2020), http://emispendis.kemenag.go.id/dashboard/?content=data. 
banyak dipelajari orang dan belum terasa kemanfaatannya dalam kehidupan baik itu di keluarga, masyarakat, bangsa dan bahkan agama. Dengan hati terus bermakrifat, nilai-nilai Islam semakin melakat dalam dunia pendidikan ${ }^{5}$.

\section{METODE}

Metode yang akan digunakan untuk pengkajian ini studi literatur. Data yang diperoleh dikompulasi, dianalisis, dan disimpulkan sehingga mendapatkan kesimpulan mengenai studi literatur. penelitian kepustakaan adalah penelitian yang dilakukan hanya berdasarkan atas karya tertulis, termasuk hasil penelitian baik yang telah maupun yang belum dipublikasikan ${ }^{6}$. Data-data yang dibutuhkan dalam penelitian dapat diperoleh dari sumber pustaka atau dokumen. Penelitian ini bertujuan untuk memperoleh gambaran mengenai konsep pendidikan sebagai upaya ma'rifatullah. Penelitian ini dilakukan untuk menyelidiki dan menggali ayat Al-Quran dan hadis untuk mengungkapkan makna ma'rifatullah yang sebenarnya. Desain penelitian ini menggunakan pendekatan kualitatif ${ }^{7}$, dengan Metode yang akan digunakan untuk pengkajian inistudi literatur. Peneliti menghimpun, mengidentifikasi, menganalisis, dan mengadakan sintesis data, untuk kemudian memberikan interpretasi terhadap konsep pendidikan sebagai upaya ma'rifatullah. Jenis data yang digunakan adalah data sekunder ${ }^{8}$. Metode pengumpulan data adalah studi pustaka ${ }^{9}$.

\section{HASIL DAN PEMBAHASAN}

\section{Ma'rifatullah dalam Al-Quran dan Hadis}

Ma'rifat dalam term-term al-Qur'an memiliki banyak arti: mengetahui, mengenal, sangat akrab, hubungan yang patut, berhubungan baik dan pengenalan berdasarkan pengetahuan mendalam. Arti ma'rifat ini berasal dari kata yang berakar pada kata 'arafa, dalam keseluruhan alQur'an disebutkan sebanyak 71 kali. Maka jika semua pengertian itu dihimpun dalam satu pengertian, ma'rifat dalam substansi al Qur'an memiliki maksud sebagai pengenalan yang baik serta mendalam berdasarkan pengetahuan yang menyeluruh dan rinci, sebagai buah hasil dari hubungan yang sangat dekat dan baik. Pengertian inilah yang berlaku pada konsep ma'rifat terhadap Allah (ma'rifatullah) ${ }^{10}$.

5 Angga Teguh Prastyo, "Nilai-Nilai Ma'rifatullah dalam Pendidikan Agama Islam (Telaah Atas Karya Muchtar Adam dan Fadlulah Muh. Said: 'Ma'rifatullah Membangun Kecerdasan Spiritual, Intelektual, Emosional, Sosial, dan Akhlakul Karimah')” (UIN Maulana Malik Ibrahim Malang, 2008).

${ }^{6}$ Melfianora, "Penulisan Karya Tulis Ilmiah Menggunakan Studi Literatur," UPT Balai Pelatihan Penyuluh Pertanian 05, no. 01 (2016): 12-25.

${ }^{7}$ Sugiyono, Metode Penelitian Kuantitatif, Kualitatif dan R\&D, 24th ed. (Bandung: Alfabeta, 2016).

${ }^{8}$ Philip Buckley and Irawan Irawan, "The Scientific Paradigm of Islamic Education Management: Phenomenology Perspective," Jurnal Pendidikan Islam 2, no. 1 (2015): 1-29.

${ }^{9}$ Ari Prayoga and Dewi Qorotul Kaffah, "Manajemen Sarana dan Prasarana Perspektif Al-quran dan Hadis," TARBIYA ISLAMIA : Jurnal Pendidikan dan Keislaman 8, no. 2 (2019): 165-179.

${ }^{10}$ Nunu Burhanuddin, “The Relationship Between Ma'Rifat and the Theory of Knowledge and Its Implication in Education,” European Journal of Educational and Development Psychology (2017). 
Untuk sampai kepada kesempurnaan ma'rifatullah, oleh karena turunnya al-Qur'an melalui kalbu Rasulullah, maka al-Qur'an juga mengisyaratkan bahwa seseorang juga harus memiliki ma'rifat terhadap rasulullah atau ma'rifatur-rasul.

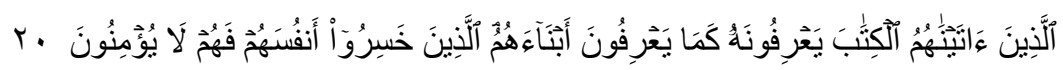

Artinya:“Orang-orang yang telah Kami berikan kitab kepadanya, mereka mengenalnya (Muhammad) seperti mereka mengenal anak-anaknya sendiri. Orang-orang yang merugikan dirinya, mereka itu tidak beriman (kepada Allah).” (Al-An'am/6: 20) ${ }^{11}$.

Jika pengenalan akan Allah sebagaimana pengenalan atas dirinya sendiri (man 'arafa nafsahu faqad 'arafa Rabbahu), maka dalam ayat tersebut ditegaskan bahwa ma'rifatur-rasul identik dengan pengenalan terhadap anak-anak kita sendiri. Jadi betapa dekatnya kita dengan Rasulullah kalau memang kita dapat ber-ma'rifat kepadanya secara benar. Sebagai bentuk aplikasi dari dua ma'rifat tersebut serta sebagai salah satu ciri telah sampainya kemanunggalan, maka alQur'an atau kitab suci dalam diri seseorang menjadi sesuatu yang bersifat aktif. Bukan sesuatu yang pasif dan hanya digunakan sebagai alat justifikasi belaka ${ }^{12}$.

Ciri pokok dari orang yang berma'rifat dalam kehidupan didunianya sebagaimana yang dikemukakan Syekh Siti Jenar di atas, bahwa mereka tidak terjebak oleh gemerlapnya dunia, serta menyikapi dunia secara wara', zuhud' dan selalu mengembalikan dirinya kepada Allah. Adapun wataknya dalam menjalankan syari'at keagamaan diisyaratkan dalam QS al-A'raf [7]: 157. Sehingga dengan segala pengetahuannya atas Kebenaran (ma'rifatullah) dan ditundukkan mutlaknya kepada Allah, maka mereka selalu tenggelam dalam kebesaran Allah. Mereka larut dalam keagungan-Nya. Sebaliknya, dalam kehidupan dunia ini Allah-pun melimpahkan sebagian kebesaran dan keagungan-Nya kepada hamba-Nya tersebut, sehingga dari diri orang yang berma'rifat dapat mucul karamah-karamah dari Allah. Mereka itulah yang disebut sebagai wali Allah atau auliya' Allah.Ayat-ayat tersebut sama-sama berbicara tentang cahaya Tuhan. Cahaya tersebut ternyata dapat diberikan Tuhan kepada hamba-Nya yang Dia kehendaki. Mereka yang mendapatkan cahaya akan dengan mudah untuk mendapatkan petunjuk hidup, sedangkan mereka yang tidak mendapatkan cahaya akan mendapatkan kesesatan hidup. Dalam ma'rifat kepada Allah, yang didapat seorang sufi adalah cahaya. Dengan demikian, ajaran ma'rifat sangat dimungkinkan terjadi dalam Islam, dan tidak bertentangan dengan Al-Quran ${ }^{13}$.

Selanjutnya di dalam hadis kita jumpai Sabda Rasulullah yang berbunyi:

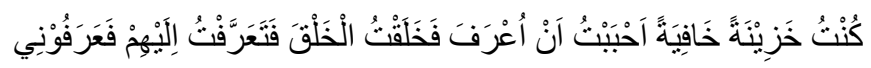

${ }^{11}$ Lajnah Pentashihan Mushaf Al-Quran (LPMQ), Elektronik Quran Kemenag, Version 2. (Jakarta: Badan Litbang dan Diklat Departemen Agama RI, 2015).

${ }^{12}$ Abdullah, "Maqamat Makrifat Hasan Al Basri dan Algazali," Al-Fikr (2016).

${ }^{13}$ Abuddin Nata, Ilmu Pendidikan Islam (Jakarta: Kencana Prenada Media Group, 2010). 
Artinya: "Aku (Allah) adalah perbendaharan yang tersembunyi (Ghaib), Aku ingin memperkenalkan siapa Aku, maka Aku ciptakanlah makhluk. Oleh karena itu Aku memperkenalkan diri-Ku kepada mereka. Maka mereka itu mengenal Aku." (Hadis Qudsi) ${ }^{14}$.

Hadis tersebut memberikan petunjuk bahwa Allah dapat dikenal oleh manusia. Caranya dengan mengenal atau meneliti ciptaan-Nya. Ini menunjukkan bahwa ma'rifat dapat terjadi dan tidak bertentangan dengan ajaran Islam.Dari segi bahasa ma'rifat berasal dari kata arafa, ya'rifu, irfan, ma'rifah yang artinya pengetahuan atau pengalaman. Dalam kitab Mu'jam al-Falsafyma'rifat diartikan sebagai pengetahuan tentang rahasia hakikat agama, yaitu ilmu yang lebih tinggi daripada ilmu yang biasa didapati oleh orang-orang pada umumnya. Ma'rifat adalah pengetahuan yang obyeknya bukan pada hal-hal yang bersifat zahir, tetapi lebih mendalam terhadap batinnya dengan mengetahui rahasianya. Hal ini didasarkan pada pandangan bahwa akal manusia sanggup mengetahui hakikat ketuhanan, dan hakikat itu satu, dan segala yang maujud berasal dari yang satu. Menurut Asmaran, ma'rifat secara etimologi berarti pengetahuan atau pengenalan. Dalam istilah sufi, ma'rifat itu diartikan sebagai pengetahuan mengenai Tuhan melalui hati (qalb). Pengetahuan itu sedemikian lengkap dan jelas sehingga jiwanya merasa menyatu dengan yang diketahuinya itu.Ma'rifat merupakan pengenalan hati terhadap objek-objek yang menjadi sasarannya. Hal ini memiliki kesamaan definisi dengan yang dikemukakan Adam, dkk. yang menyatakan bahwa ma'rifat adalah pengetahuan tentang Tuhan dari dekat, sehingga hati sanubari dapat melihat Tuhan $^{15}$.

Dalam arti sufistik, Al-Kalabazi berpendapat bahwa ma'rifat diartikan sebagai pengetahuan mengenai Tuhan melalui hati sanubari. Pengetahuan itu demikian lengkap dan jelas hingga jiwanya merasa satu dengan yang diketahuinya itu, yaitu Tuhan. Menurut Kartanegara, ma'rifat adalah sejenis pengetahuan dengan mana para sufi menangkap hakikat atau realitas yang menjadi obsesi mereka. Ma'rifat berbeda dengan jenis pengetahuan lainnya, karena ia menangkap objeknya secara langsung, tidak melalui representasi, image atau simbol dari objek-objek penelitiannya itu. Selanjutnya, lebih jelas lagi al-Jailani berpendapat bahwa ma'rifatullah (mengenal Allah) adalah membangun kesadaran dalam hati bahwa Allah begitu dekat dengan dirinya, selalu menjaganya, berkuasa atas dirinya, menyaksikannya, dan mengetahui segala tindaktanduknya ${ }^{16}$.

Dari beberapa definisi di atas maka dapat diketahui bahwa ma'rifat adalah mengetahui rahasia-rahasia Tuhan dengan menggunakan hati. Dengan demikian tujuan yang ingin dicapai oleh ma'rifat ini adalah mengetahui rahasia-rahasia yang terdapat dalam diri Tuhan. Mengenai

14 Abdul Fatah Idris, "Memahami Kembali Pemaknaan Hadis Qudsi," International Journal Ihya' 'Ulum al-Din (2017).

${ }^{15}$ S. M. Amin, Ilmu Tasawuf, ed. A. Zirzis and N. Laily (Jakarta: Amzah, 2012).

${ }^{16}$ S. A. Al-Jailani, Al-Tashawwuf dalam Al-Gunyah Lithalibi, ed. J. Rofarif and A. Irawan (Jakarta: Zaman, 2012). 
kedudukan ma'rifat, dalam pandangan al-Junaid, ma'rifat ini dianggap sebagai hal, sedangkan dalam risalah al-Qusyairiyah, ma'rifat dianggap sebagai maqam. Kedudukan ma'rifah dekat dengan muhabbah. Imam al-Ghazali memandang ma'rifat datang sebelum mahabbah. Sedangkan al-Kalabazi berpendapat sebaliknya. Selain itu adapula yang berpendapat bahwa ma'rifat dan mahabbah ini merupakan kembar dua yang selalu disebut berbarengan. Keduanya sama-sama menggambarkan keadaan dekatnya hubungan seorang sufi dengan Tuhan.Adapun alat untuk mencapai ma'rifat telah ada pada diri manusia, yaitu qalb (hati). Qalb yang telah dibersihkan dari segala dosa dan maksiat dengan serangkaian dzikir dan wirid secara teratur akan dapat mengetahui rahasia-rahasia Tuhan, yaitu setelah hati tersebut disinari cahaya Tuhan ${ }^{17}$.

Dalam literatur tasawuf dijumapi dua orang tokoh yang mengenalkan paham ma'rifat ini, yaitu Al-Ghazali dan Zun al-Nun al-Misri. Selain itu ada juga ada Harits Al-Muhasibi yang juga memiliki konsep tentang ma'rifat ini.Ma'rifat al-Ghazali tidak seperti ma'rifat menurut orang awam maupun ma'rifat ualam/mutakallimin, tetapi ma'rifat sufi yang dibangun atas dasar $d z u q$ rohani dan kasyf Illahi.Al-Ghazali memberikan pandangannya tentang ma'rifat yaitu tampak jelas rahasia-rahasia ketuhanan dan pengetahuan mengenai susunan urusan ketuhanan yang mencakup segala yang ada. Lebih lanjut al-Ghazali mengatakan bahwa ma'rifat adalah memandang kepada wajah (rahasia) Allah. Sementara itu, M. Zahri menjelaskan bahwa ma'rifat yang dimunculkan oleh Zun al-Nur al-Misri adalah pengetahuan hakiki tentang Tuhan. Menurutnya ma'rifat hanya terdapat pada kaum sufi yang sanggup melihat Tuhan dengan hati sanubari mereka. Pengetahuan serupa ini hanya diberikan Tuhan kepada kaum sufi. Ma'rifat dimasukkan Tuhan ke dalam hati seorang sufi, sehingga hatinya penuh dengan cahaya. Ketika Zun al-Nur al-Misri ditanya bagaimana ia memperoleh ma'rifat tentang Tuhan, ia menjawab: aku mengetahui Tuhan dengan Tuhan dan sekiranya tidak karena Tuhan aku tak akan tahu Tuhan ${ }^{18}$.

\section{Telaah Teologis Terkait Pendidikan Sebagai Upaya Ma'rifatullah}

Affandi menjelaskan beberapa manifestasi dari ma'rifat ke dalam tiga jenis zikir, antara lain: (1) Zikir Lisan, yakni dengan mengucapkan atau mengamalkan ataupun juga membaca zikir yang sembilan (tasbih, tahmid, takbir, tahlil, hauqalah, istighfar, shalawat, membaca Alquran, dan doa). (2) Zikir fisik (anggota badan), yaitu dengan memanfaatkan setiap gerak langkah di jalan allah, yaitu dengan cara melaksanakan perintah Allah swt baik mahdhah; shalat, puasa, haji maupun ibadah ghair mahdhah; menolong orang lain, memperbaiki jalan umum, dan lain-lain. (3) Zikir jinan (Hati), yaitu dengan mengingat Allah di dalam hati, baik diwujudkan melalui lisan,

${ }^{17}$ Nata, Ilmu Pendidikan Islam, h. 235.

${ }^{18}$ A. Zaini Dahlan et al., "Konsep Makrifat Menurut Al-Ghazali dan Ibnu 'Arabi: Solusi Antisipatif Radikalisme Keagamaan Berbasis Epistemologi,” Jurnal Kawistara 03, no. 01 (2013): 68-78. 
tafakur (berfikir), atau tadzakur (berdzikir). Menurutnya lagi, ada satu ibadah yang mencakup ketiga macam zikir di atas, yaitu shalat ${ }^{19}$.

Melihat penjelasan di atas, penulis berpendapat bahwa tidak terlalu sulit jika kita ingin mengimplementasikan ma'rifat dalam kehidupan masa kini. Teori yang disajikan sangat mudah dipahami dan kemungkinan besar bisa kita laksanakan di abad modern ini, namun dalam prakteknya apakah akan mudah juga?. Jika kita pandang secara sederhananya, ma'rifat bisa diartikan dengan mengenal Allah atau merasakan kehadiran Allah. Allah harus menjiwai seluruh aktifitas kita. Tidak jauh berbeda dengan konsep iman, Allah harus diyakini dengan hati tentang kehadiran-Nya, diucapkan dengan lisan melalui lantunan dzikir, dan menjadi ruh dalam segala amalan lahiriah kita baik yang mahdhah maupun ghair mahdhah. Kita tidak harus selalu berdiam diri seharian suntuk atau beberapa hari lamanya di dalam masjid, atau di dalam gua sekalipun untuk merasakan kehadiran Allah ${ }^{20}$.

Seperti yang telah dijelaskan di atas bahwa alat untuk meraih ma'rifat adalah hati. Jadi kunci utama dari ma'rifat ini ialah hati. Di mana pun dan dalam keadaan apa pun hati harus senantiasa mengingat Allah, menghadirkan Allah. Warnai semua aktifitas kita yang seharisemalamnya cukup padat itu dengan kehadiran-Nya. Dengan demikian segala aktifitas yang kita lakukan itu tidak akan sia-sia. Jika kita telah berhasil berma'rifat maka insya Allah kita akan senantiasa berhati-hati dalam bertindak, khusyu dalam beribadah, rendah hati, terhindar dari sifat angkuh, tinggi hati, riya, sum'ah dan sejenisnya pun ia tidak menjadi orang yang kikir karena ia malu kepada Allah, ia selalu merasa bahwa semua yang ia lakukan Allah melihatnya, Allah mengetahuinya. Ia meyakini bahwa segala sesuatu yang ia punya adalah milik Allah.Perlu kita ketahui bahwa ma'rifat ini tidak akan pernah dicapai tanpa perjuangan yang sungguh-sungguh. Bahan bakar berupa niat yang lurus, mujahadah dan istiqomah sangat diperlukan dalam perjalanan menuju ma'rifatullah ini. Secara teologi konsep ma'rifatullah ini sangat layak diterapkan dalam dunia pendidikan. Karena sejatinya pendidikan merupakan upaya untuk memperbaiki diri dan semakin dekat dengan Allah. Sebagaimana dalam ajaran Islam untuk menumbuhkan nilai-nilai moralitas dikenal sebagai nilai-nilai spiritual. Untuk dapat menghadirkan nilai-nilai spiritual, perlu menumbuhkan kesadaran ilāhiyya untuk mendekatkan diri kepada Allah ${ }^{21}$.

Untuk meningkatkan nilai spiritual, ada langkah dan upaya yang harus dilakukan seseorang, yakni tazkiyatu al-nafs, mujāhadah, dan riyādah. Bagi seseorang yang akan menjalani kehidupan tasawuf harus menempuh maqam-maqam (tahapan spritual), yakni taubat, zuhud, faqir, sabar, tawakal dan ikhlas. Bagi seseorang yang menjalani tasawuf, setelah menempuh maqam

${ }^{19}$ C Affandi, La Tahzan Innallaha Ma'ana: Bersama Allah di Setiap Tempat dan Waktu (Bandung: Mizan Pustaka, 2007).

${ }^{20}$ Ari Prayoga and Mohammad Sulhan, "Pesantren Sebagai Penangkal Radikalisme dan Terorisme" 5, no. 2 (2019): 163-177.

${ }^{21}$ Sodiman. "Menghadirkan Nilai-Nilai Spritual Tasawuf dalam Proses Mendidik." Jurnal Al-Ta'dib 6, no. 1 (2014): 330-344. 
(kedudukan atau tahapan spiritual), maka akan merasakan kondisi spiritual yakni muraqabah, qurbah, muhabbah, khauf, raja', syauq, uns dan musyahadah ${ }^{22}$. Untuk mencapai demikian, diperlukan beberapa proses yang harus dilalui terlebih dulu, yakni proses takhalī (pengosongan hati dari sifat tercela), tahalī (pengisian hati dari sifat terpuji), dan tajalī (pendekatan diri kepada Allah). Dengan demikian konsep ini mampu mengantarkan kita menuju ma' 'rifatullah ${ }^{23}$.

Menurut al-Ghazali ma'rifatullah merupakan sumber dan puncak kelezatan beribadah yang dilakukan oleh seorangmanusia di dunia ini. Lebih jauh lagi Ia memberi pandanganyang luas tentang kebahagiaan dan kelezatan bagi manusia untuk mencapai ma'rifatullah. Mengenal dan mencintai Sang Pencipta dengan sepenuhnya. Dengan demikian manusia akan memperoleh yang luar biasa dari yang lainnya. Ma'rifat kepada Allah adalah sifat yang sangat mulia ${ }^{24}$. Dengan hati terus bermakrifat, nilai-nilai Islam semakin melekat. Islam sangat menjunjung tinggi nilai-nilai humanisme dan memelihara kemaslahatan hidup manusia, menjaga dan memelihara akal, jiwa, harta, keturunan, dan harga diri, termasuk amar ma'rüf dan nahī munkar yang menjadi spirit pola kehidupan kaum muslimin ${ }^{25}$. Sehingga manusa dijadikan sebagai cermin yang dapat mendeteksi Ilāhi ${ }^{26}$.

Para pakar pendidikan Islam menjabarkan makna pendidikan untuk membebaskan diri dari kungkungan hawa nafsu dan keyakinan-keyakinan yang tak berdasar pengetahuan yang benar, yaitu hanya sekedar tradisi dan kebiasaan. Pendidikan Islam berupaya agar manusia mampu mengikatkan diri pada bimbingan Tuhan, yaitu ajaran agama, suatu spiritualitas yang memiliki rujukan yang benar ${ }^{27}$. Juga sebagai penyambung risalah Nabi yang senantiasa tercerahkan dalam pengetahuan Ilahi $^{28}$. Dengan kembali ke keadaan primordial (fitrah), dan ke realitas diri sebagai hamba Allah yang setia, sadar akan dirinya sebagai wakil Allah (khalifah), mewujudkan kefanaan, dan akhirnya, melalui peniadaan ego, bersama akal dalam diri, mencapai Zat Tertinggi, Sang Realitas ${ }^{29}$.

${ }^{22}$ Fakhruddin, Agus. "Urgensi Pendidikan Nilai Untuk Memecahkan Problematika Nilai dalam Konteks Pendidikan Persekolahan.” Jurnal Pendidikan Agama Islam-Ta'lim 12, no. 1 (2014): 79-96.

${ }^{23}$ Setiawan, Wahyudi. "The Spiritual Education Toward Insan Kamil in the Education of Modern Humankind," no. October (2016): 1-7.

${ }^{24}$ Ibid. 126.

${ }^{25}$ Sukarman. "Urgensi Pendidikan Holistik dalam Membentuk Insan Kamil." Jurnal Tarbawi 2, no. 2 (2014): 3102.

${ }^{26}$ Kaya, Cinar. "Rumi from the Viewpoint of Spiritual Psychology and Counseling." Spiritual Psychology and Counseling 1, no. 1 (2016): 5-21.

${ }^{27}$ Rizal, Ahmad Syamsu. "FILSAFAT PENDIDIKAN ISLAM ISLAMI" Jurnal Pendidikan Agama Islam - Ta'lim 12, no. 1 (2014): 1-18.

${ }^{28}$ Dewi, Ernita. "Konsep Manusia Ideal dalam Persepektif Suhrawardi Al-Maqtul.” Substantia 17, no. 1 (2015): 41-54.

${ }^{29}$ Subhi, Mohamamad. "Doktrin Manusia Universal dalam Antropologi Metafisis Seyyed Hossein Nasr.” Jurnal Universitas Paramadina 11, no. 3 (2014): 1128-1145. 


\section{Implikasi Konsep Ma'rifatullah terhadap Teori Pendidikan Islam}

Ma'rifatullah merupakan konsep yang sempurna untuk mengantarkan tujuan pendidikan menjadi bermakna, selain itu juga memberikan makna pada komponen pendidikan yang sangat bernilai. Penulis memvisualisasikan implikasi konsep ma'rifatullah ke dalam bentuk bagan berikut:

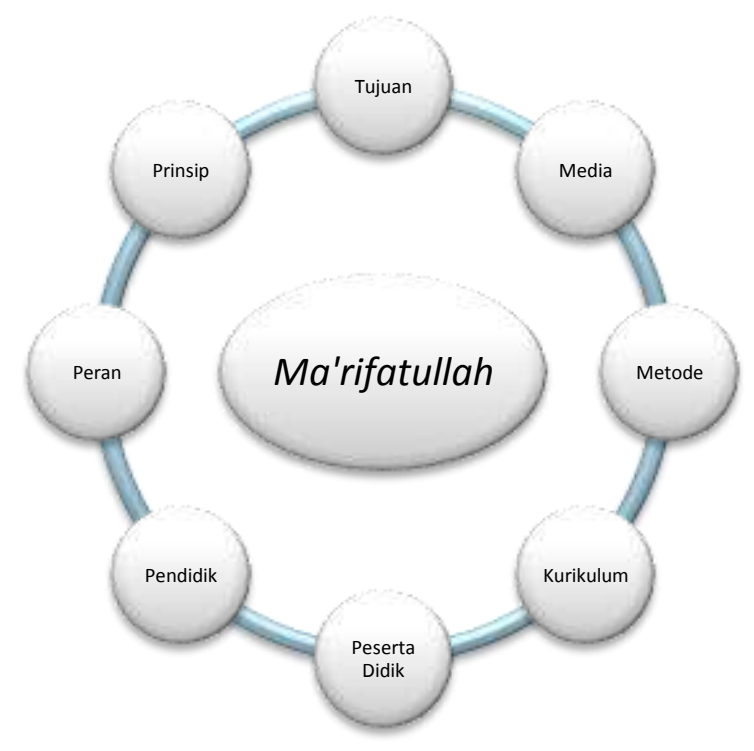

Gambar 1. Implikasi Edukatif Konsep Ma'rifatullah

Pengertian pendidikan Islam merupakan sebuah upaya penyadaran status manusia sebagai hamba Allah dan perannya sebagai khalifatullah, serta proses menumbuhkembangkan, menguatkan dan mengaktualisasikan seluruh potensi yang dimiliki dalam kehidupan sehari hari agar dapat menggapai ma'rifatullah. Tujuan pendidikan Islamialah menyempurnaan iman, taqwa, dan akhlak, serta aktif membangunperadaban bangsa yang bermartabat dengan ma'rifatullah. Hal ini selaras dengan ungkapan Rizal bahwa dengan terbinanya sikap religius baik pada pola pikir, sikap hidup, serta memanfaatkan kemampuan untuk kehidupan manusia dengan motif untuk memperoleh ridho Allah dalam menggapai ma'rifatullā $h^{30}$.

Peran dan Fungsi Pendidikan Islam ialah sebagai fasilitator dalam mengembangkan potensi untuk ma'rifatullah dengan akklah yang baik. Sebagaimana Nata mengungkapkan dalam bukunya bahwa peran atau fungsi pendidikan juga sebagai upaya meningkatkan kecerdasan emosional. Dapat disebut demikian karena di dalam dunia pendidikan khususnya dalam pendidikan Islam diajarkan pengetahuan mengenai bagaimana cara manusia berakhlak. Dengan itu potensi emosional yang ada dalam diri manusia dapat dikembangkan dan diarahkan ke dalam emosi yang positf.Prinsip Pendidikan Islam yang tersirat dalam konsep ma'rifatullah ialah prinsip-prinsip

${ }^{30}$ Rizal, Ahmad Syamsu. "Filsafat Pendidikan Islam Islami” Jurnal Pendidikan Agama Islam - Ta'lim 12, no. 1 (2014): 1-18. 
Raḥmāniyyah (Kasih Sayang) dan prinsip Raḥmāniyyah (Kasih Sayang), karena manusia harus senantiasa diberikan pendidikan dengan penuh kasih sayang dan kehangatan iman yang kuat sedari dini. $^{31}$

Karena pendidik dalam pendidikan Islam memiliki tanggung jawab yang sangat berat untuk membina potensi manusia agar ma'rifatullah, yang tentunya karakteristik seorang pendidik harus memiliki kekuatan spiritual yang mengantarkan dirinya menuju ma'rifatullah. Hal ini sepadan dengan apa yang dikemukakan oleh Tafsir bahwa pendidik ialah siapa saja yang bertanggung jawab terhadap perkembangan anak didik dengan mengupayakan perkembangan seluruh potensinya, baik potensi afektif, kognitif, maupun psikomotorik sesuai dengan nilai-nilai ajaran Islam ${ }^{32}$. Sementara itu, peserta didik dalam pendidikan Islam merupakan seorang yang sedang berupaya mengembangkan potensinya dengan baik. Sebagaimana dalam UU sisdiknas pasal 1 ayat 4 dinyatakan bahwa peserta didik adalah anggota masyarakat yang berusaha mengembangkan potensi diri melalui proses pembelajaran yang tersedia pada jalur, jenjang, dan jenis pendidikan tertentu ${ }^{33}$.

Adapun isi dari kurikulum pendidikan Islam yang berfokus kepada materi pendidikan Islam, diantaranya menurut Ibn Khaldun yang diungkapkan oleh Muhammad 'Athiyah al-Abrasyi terbagi menjadi dua tingkatan. Pertama, tingkat pemula (manhāj ibtidā'i) berfokus pada pembelajaran Alquran dan al-Sunnah. Kedua, tingkat atas (manhāj 'a $\bar{a} l \bar{l}$ ) dimana pada tingkatan ini memiliki dua kualifikasi, yakni 1) ilmu-ilmu yang berkaitan dengan zatnya sendiri, seperti ilmu syari'ah yang mencakup fikih, tafsir, hadis, ilmu kalām, ilmu bumi dan filsafat. 2) Ilmu yang ditujukan untuk ilmu-ilmu lain, seperti ilmu kebahasaan, ilmu matematik dan ilmu logika (manțiq). Kesemua materi ditujukan untuk ma'rifatullah. Sehingga materi pun disampaikan harus dengan pemilihan metode yang tepat dan sesuai.

Adapun beberapa metode pendidikan Islam yang perlu diterapkan di sekolah, beberapa di antaranya adalah sebagai berikut: (1) Metode Ams்āl, yakni metode perumpamaan.(2) Metode kisah Qurāni, yakni metode yang diambil dari kisah-kisah atau peristiwa yang terjadi pada umat terdahulu (3) Metode 'Ibraћ Maw'izah, yakni metode berupa pengambilan pelajaran dan pemberian nasehat. (4) Metode Targib-Tarhib, yakni metode yang menggunakan strategi bujukan dan ancaman. (5) Metode Uswāh Hasanah, yakni metode pemberian teladan yang baik. (6) Metode Hiwār Qurāni, yakni metode yang memberlakukan sistem dialog, mengadakan suatu percakapan atau pembicaraan yang silih berganti antara dua pihak atau lebih yang dilakukan melalui tanya jawab $^{34}$.

\footnotetext{
${ }^{31}$ Nata, Ilmu Pendidikan Islam, h. 52.

${ }^{32}$ Ahmad Tafsir, Pendidikan Budi Pekerti (Bandung: Maestro, 2009).

${ }^{33}$ B. Umar, Hadis Tarbawi Pendidikan Dalam Perspektif Hadis (Jakarta: Amzah, 2012).

${ }^{34}$ Affandi, La Tahzan Innallaha Ma'ana: Bersama Allah di Setiap Tempat dan Waktu.
} 
Demikian metode Qurani ini bisa menjadi alternatif untuk mencapai ma'rifatullah, yang tentunya dengan menggunakan pilihan media pendidikan yang tepat pula. Hamalik mengemukakan bahwa pemakaian media pembelajaran dalam suatu proses belajar mengajar dapat membangkitkan keinginan dan minat yang baru, membangkitkan motivasi dan rangsangan kegiatan belajar, dan bahkan membawa pengaruh-pengaruh psikologi terhadap siswa. Di antara media pendidikan yang bisa mengantarkan kita menuju ma'rifatullah ialah media yang berkaitan dengan tafakur alam semesta.

\section{KESIMPULAN}

Kesimpulan dalam pembahasan penelitian ini yaitu konsep ma'rifatullah diartikan sebagai pengetahuan mengenai Tuhan melalui hati sanubari. Ma'rifat adalah mengetahui rahasia-rahasia Tuhan dengan menggunakan hati. Dengan demikian tujuan yang ingin dicapai oleh ma'rifat ini adalah mengetahui rahasia-rahasia yang terdapat dalam diri Tuhan. Adapun alat untuk mencapai ma'rifat telah ada pada diri manusia, yaitu qalb (hati). Qalb yang telah dibersihkan dari segala dosa dan maksiat dengan serangkaian dzikir dan wirid secara teratur akan dapat mengetahui rahasiarahasia Tuhan, yaitu setelah hati tersebut disinari cahaya Tuhan. Konsep ma'rifat ini merupakan tujuan pendidikan yang utama, yang mana manifestasi ma'rifat dapat kita lakukan dengan memperbanyak zikir lisan, zikir fisik dan zikir hati. Adapun implikasi edukatif dari konsep ini meliputi tujuan, peran, fungsi, prinsip, pendidik, peserta didik, materi, metode dan media pendidikan. Kesemuanya itu harus memberikan pengaruh positif pada akal dan hati dalam meningkatakan seluruh potensi yang dimiliki oleh manusia. Dengan demikian, seluruh kompenen pendidikan tersebut diarahkan menuju makrifatullāh.

\section{DAFTAR RUJUKAN}

Abdullah. "Maqamat Makrifat Hasan Al Basri dan Algazali.” Al-Fikr (2016).

Affandi, C. La Tahzan Innallaha Ma'ana: Bersama Allah di Setiap Tempat dan Waktu. Bandung: PT. Mizan Pustaka, 2007.

Al-Jailani, S. A. Al-Tashawwuf dalam Al-Gunyah Lithalibi. Edited by J. Rofarif and A. Irawan. Jakarta: Zaman, 2012.

Amin, S. M. Ilmu Tasawuf. Edited by A. Zirzis and N. Laily. Jakarta: Amzah, 2012.

Arsyad, A. Media Pembelajaran. Jakarta: Rajawali Pers, 2011.

B, Muhammad Rusmin. “Konsep dan Tujuan Pendidikan Islam.” Jurnal Taklim 06, no. 01 (2004): 72-80.

Bagian Data Sistem Informasi dan Humas. "EMIS Dashboard Pendis Kemenag Rekapitulasi Data Pesantren Dan Diniyah.” Jakarta: Dirjen Pendidikan Islam, July 2020. http://emispendis.kemenag.go.id/dashboard/?content=data. 
Buckley, Philip, and Irawan Irawan. "The Scientific Paradigm of Islamic Education Management: Phenomenology Perspective.” Jurnal Pendidikan Islam 2, no. 1 (2015): 1-29.

Burhanuddin, Nunu. "The Relationship Between Ma'Rifat and the Theory of Knowledge and Its Implication in Education." European Journal of Educational and Development Psychology (2017).

Dahlan, A. Zaini, Siti Chamamah Soeratno, Sangidu Sangidu, and Ahmad Mursyid. "Konsep Makrifat Menurut Al-Ghazali Dan Ibnu 'Arabi: Solusi Antisipatif Radikalisme Keagamaan Berbasis Epistemologi.” Jurnal Kawistara 03, no. 01 (2013): 68-78.

Haningsih, Sri. "Peran Strategis Pesantren, Madrasah dan Sekolah Islam di Indonesia." el-Tarbawi (2008).

Idris, Abdul Fatah. "Memahami Kembali Pemaknaan Hadis Qudsi." International Journal Ihya' 'Ulum al-Din (2017).

Lajnah Pentashihan Mushaf Al-Quran (LPMQ). Elektronik Quran Kemenag. Version 2. Jakarta: Badan Litbang dan Diklat Departemen Agama RI, 2015.

Melfianora. "Penulisan Karya Tulis Ilmiah Menggunakan Studi Literatur." UPT Balai Pelatihan Penyuluh Pertanian 05, no. 01 (2016): 12-25.

Murni. "Konsep Ma'rifatullah Menurut Al-Ghazali (Suatu Kajian Tentang Implementasi NilaiNilai Akhlak Al-Karimah)." Ar-Raniry: International Journal of Islamic Studies 02, no. 01 (2015): 123-146. www.journalarraniry.com.

Nata, Abuddin. Ilmu Pendidikan Islam. Jakarta: Kencana Prenada Media Group, 2010.

Prastyo, Angga Teguh. "Nilai-Nilai Ma'rifatullah dalam Pendidikan Agama Islam (Telaah Atas Karya Muchtar Adam Dan Fadlulah Muh. Said: 'Ma'rifatullah Membangun Kecerdasan Spiritual, Intelektual, Emosional, Sosial, dan Akhlakul Karimah').” UIN Maulana Malik Ibrahim Malang, 2008.

Prayoga, Ari, and Dewi Qorotul Kaffah. "Manajemen Sarana dan Prasana Perspektif Al Quran dan Hadis." TARBIYA ISLAMIA : Jurnal Pendidikan dan Keislaman 8, no. 2 (2019): 165-179.

Prayoga, Ari, and Mohammad Sulhan. "Pesantren Sebagai Penangkal Radikalisme dan Terorisme" 5, no. 2 (2019): 163-177.

Sugiyono. Metode Penelitian Kuantitatif, Kualitatif dan R\&D. 24th ed. Bandung: Alfabeta, 2016.

Tafsir, Ahmad. Pendidikan Budi Pekerti. Bandung: Maestro, 2009.

Umar, B. Hadis Tarbawi Pendidikan dalam Perspektif Hadis. Jakarta: Amzah, 2012. 